\title{
Custos Sociais e Orçamentários das Políticas de Garantia de Preços no Brasil - estudo dos casos de arroz e milho ${ }^{1}$
}

\author{
Fernanda Schwantes ${ }^{2}$ e Carlos José Caetano Bacha ${ }^{3}$
}

Resumo: O objetivo geral deste artigo é mensurar os custos sociais e orçamentários da política de garantia de preços para o arroz e o milho de 1986/87 a 2012/13. Nesse período, ocorreram importantes mudanças na Política de Garantia de Preços Mínimos (PGPM) e os dois produtos citados foram, sistematicamente, atendidos pela PGPM. Para tanto, desenvolveram-se modelos matemáticos para calcular o custo social para três políticas de garantia de preços mínimos (preço subsídio, aquisições do governo e seguro de preços) e esses custos sociais foram estimados apenas quando o preço mínimo superou o preço de mercado. Constatou-se que houve operacionalização das políticas de PGPM mesmo quando o preço mínimo esteve abaixo do preço de mercado. Ao se comparar os custos sociais com os custos orçamentários nos anos-safra supracitados, verificou-se que, de modo geral, o custo social por tonelada de arroz e de milho foi menor para o programa de seguro de preços, seguido do preço subsídio e das aquisições do governo. Esses resultados auxiliam na escolha futura de qual instrumento de PGPM se utilizar.

Palavras-chaves: Política de garantia de preços, custo social, custo orçamentário, arroz, milho.

Abstract: This paper aims to measure the social and budgetary costs of the price guarantee policy for rice and corn in the period from 1986/87 to 2012/13. These years faced important changes in the mentioned policy and both products have been systematically afforded by this policy. The paper develops mathematical models to calculate the social cost for three price guarantee policies (price subsidies, government purchases and price insurance) and the social costs were estimated only when the minimum price exceeds the market price. It was verified that PGPM policies were operationalized even when the minimum price was below the market price. Comparing social and budgetary costs during the above crop years for each ton of rice and corn, in general, it was found that the lowest social cost was for a

1. Data de submissão: 30 de novembro de 2015. Data de aceite: 23 de abril de 2017.

2. Confederação da Agricultura e Pecuária do Brasil. Brasília, Distrito Federal, Brasil. E-mail: fe.schwantes@gmail.com

3. Escola Superior de Agricultura Luiz de Queiroz/Universidade de São Paulo. Piracicaba, São Paulo, Brasil. E-mail: carlosbacha@usp.br 
price insurance program, followed by subsidy price programs and the highest social cost arises for the purchasing programs. The findings would help policy-makers when deciding what kind of price guarantee policy needs to be performed.

Key-words: Price guarantee policy, social cost, budget cost, rice, corn.

\section{Introdução}

A agropecuária assume papéis importantes no desenvolvimento econômico de diversos países, inclusive o Brasil, fornecendo alimentos, capitais para o setor não agropecuário, divisas para as importações, mão de obra para o setor não agropecuário, matérias-primas para a indústria e constituindo-se em mercado consumidor (ARAÚJO e SCHUH, 1998). Para atender a esses papéis, a execução de políticas agrícolas é importante, destacando-se, entre elas, a de sustentação de preços (conforme mostram GOLDIN e REZENDE, 1993; BACHA, 2012).

As oscilações dos preços agrícolas têm impactos negativos significativos sobre todos os segmentos de uma cadeia agroindustrial. Pelo lado da oferta, os produtores rurais estão expostos à incerteza de obtenção de renda, advinda da instabilidade de preços ao longo de um ano-safra e mesmo entre anos-safra, o que impõe dificuldades para o planejamento da produção. Pelo lado da demanda, os consumidores estão sujeitos aos riscos da não regularidade da oferta de alimentos (ou do abastecimento do mercado) e do crescimento acentuado dos seus preços.

Buscando reduzir a instabilidade dos preços agrícolas, assegurar uma renda mínima aos produtores e, principalmente, garantir o abastecimento interno de alimentos, foi criada a Comissão de Financiamento da Produção (CFP), por meio do Decreto 5.212/1943. Esse foi o primeiro movimento em direção à criação da Política de Garantia de Preços Mínimos (PGPM) no Brasil, lançada oficialmente em 1966 (COLOMBINI, 2008$, p. 75$)^{4}$. A PGPM constitui-se em um mecanismo específico de política de rendas ${ }^{5}$, de modo que, ao adotar essa política, o governo exerce controle sobre os preços dos produtos agropecuários, evita a queda drástica desses preços em períodos de oferta abundante (durante a safra, por exemplo), busca a manutenção de um nível mínimo de renda para o produtor rural, e, também, defende a renda do consumidor, inibindo o crescimento dos preços dos produtos agropecuários (VERDE, 2001, p. 316). Para executar a política de preços

4. Segundo Coelho (2001), a Comissão de Financiamento da Produção (CFP) foi criada na fase que o autor classifica a política agrícola no Brasil como "fase da agricultura primitiva", de 1930 a 1965 . Esta fase contempla a criação de vários órgãos reguladores, enquanto a PGPM em si foi criada em 1966, instituindo normas para a fixação de preços mínimos, para a execução das operações de financiamento e de aquisição de produtos agrícolas, na "fase de modernização da agricultura", ocorrida de 1965 a 1985.

5. Segundo Bacha (2012, p. 52), "a política de rendas constitui-se em uma série de regulamentações que restringem a produção e a comercialização de produtos, bem como o uso dos fatores de produção; e/ou determina valores mínimos ou máximos para pagamento pelo uso desses fatores ou por produtos elaborados em uma economia. (...) As políticas de rendas materializam-se na forma de legislação (leis, decretos, portarias, por exemplo) que definem as regulamentações sobre como e quanto utilizar de fatores de produção e que preços pagar ou cobrar por serviços de fatores de produção e preços de bens e serviços". 
mínimos, recursos públicos são necessários, vinculando-se, portanto, a execução da PGPM à política fiscal do governo.

Desde o lançamento da PGPM até meados da década de 1990, a operacionalização dessa política ocorria, basicamente, por meio de dois instrumentos: as Aquisições do Governo Federal (AGF) ${ }^{6}$ e os Empréstimos do Governo Federal (EGF). Stefanelo (2005, p. 51) classificou esses instrumentos de atuação da PGPM no País como mecanismos de intervenção ampla no mercado, na medida em que qualquer produtor pode vender a sua produção ao governo federal, desde que este último tenha recursos suficientes para adquiri-la.

Na década de 1990, as mudanças estruturais liberalizantes e o novo modelo de apoio à agropecuária levaram a profundas mudanças na forma de operação das políticas agrícolas, incluindo as modificações nos instrumentos de apoio à comercialização de produtos agrícolas, conforme discutido nos trabalhos de Rezende (2000 e 2001), Lamounier e Silva (2000), Verde (2001), Pereira e Prado (2002), Conceição (2003), Del Grossi e Bacha (2005) e Almeida (2014). No Plano Safra 1996-1997, o governo adicionou aos instrumentos tradicionais de operacionalização da PGPM o Prêmio para Escoamento de Produto (PEP) e o Contrato de Opção de Venda de Produtos Agrícolas (COVPA $)^{7}$, reduzindo drasticamente a

6. As Aquisições do Governo Federal (AGF) foram regulamentadas pelo Decreto-lei n. 79, de 1966.

7. "O Prêmio para Escoamento de Produto, definido como uma subvenção do governo federal foi, de certa forma, um aperfeiçoamento do PL | PE (Prêmio de Liquidação do EGF | Prêmio para Equalização de EGF) e estava implícito na Lei n. 8.427, de 27/05/1992. Entretanto, para se ter uma sustentação jurídica mais forte, a Medida Provisória n. 1.512-8, de 14/03/97, com reedições sucessivas (MP 1.692, MP 1.764 e MP 1.886-41, de 24/09/1999), foi instituída, até sua conversão na Lei n. 9.848, de 26/10/1999, que explicitou de forma clara a possibilidade de equalização de preços na forma do PEP. Ainda, o Regulamento para Oferta de Prêmio para o Escoamento de Produto, n. 001/97 da Conab, de 08/05/1997, definiu o instrumento de PGPM denominado PEP" (PEREIRA; PRADO, 2002, p. 44). "O Contrato de Opção de Venda de Produtos Agropecuários foi instituído pela Resolução BCB 2.260, de 23/03/1996, e regulamentado por meio da Portaria n. 001/97, de 28/02/1997. Os COVPA passaram a ser utilizados pelo governo federal a partir de 1997 na comercialização do milho" (CONCEIÇÃ̃O, 2003, p. 9-10). operacionalização do EGF-COV, que, a partir de 1999, assumiu valores irrisórios (BACHA, 2012, p. 76). Esses dois novos mecanismos criados a partir de 1996/1997 são classificados por Stefanelo (2005, p. 51) como instrumentos públicos de intervenção direcionada no mercado.

A partir de 2003, com a atenção do governo Lula voltada às questões sociais, foi criado o Programa Fome Zero e retomou-se o papel do Estado como formador de estoques públicos, por meio das compras da agricultura familiar (CAF), um caso específico de AGF. Para a agropecuária não familiar, o governo federal lançou, entre dezembro de 2004 e junho de 2006, dois novos instrumentos de operacionalização da PGPM, os instrumentos público/privado de intervenção direcionada no mercado, segundo Stefanelo (2005, p. 51) e Bacha e Caldarelli (2008): os Contratos Privados de Opção de Venda e Prêmio de Risco de Opção Privada (Prop) e o Prêmio Equalizador Pago ao Produtor (Pepro) ${ }^{8}$.

A política de garantia de preços como mecanismo de apoio à comercialização das safras agrícolas tem caráter dicotômico, como ressaltam Paniago e Schuh (1977). Por um lado, ela conduz à redução da instabilidade de preços no setor agrícola, exercendo seu objetivo principal, de diminuir as flutuações da renda da agropecuária. Por outro lado, esta política acarreta custos para a sociedade em geral (custos sociais). O custo social decorrente de uma política de preços mínimos, orientada no sentido de garantir preços acima do equilíbrio de mercado, depende da forma como a política é executada (OLIVEIRA, 1974b).

A intervenção do governo sobre o excesso estrutural de oferta pode ser feita por meio da compra da produção excedente ao preço mínimo garantido e manutenção de estoques reguladores, como é o caso das aquisições do governo federal (AGF) e das compras da agricultura familiar (CAF), ou por meio do subsídio aos agricultores da diferença entre o preço mínimo garantido e o preço conseguido no mercado para a produ-

8. O Prop foi criado em 31/12/2004, por meio da Lei n. 11.076, e o Pepro foi lançado em 21/06/2006 (BACHA, 2012, p. 84-85). 
ção, caso do PEP e do Pepro, ou, ainda, por meio de uma política de seguro de preços, caso do COVPA e do Prop. Destarte, torna-se importante avaliar os custos sociais e os orçamentários da utilização dos instrumentos de operacionalização da PGPM para atender aos seus objetivos de redução da instabilidade de preços no setor agrícola, orientação da produção agrícola e normalização do funcionamento do mercado, evitando excesso ou escassez de ofertas sazonais e oscilações bruscas nos preços pagos pelos consumidores.

A análise da evolução dos custos sociais e orçamentários da PGPM no Brasil ganha importância à medida que os instrumentos de execução da política foram sendo modificados, a fim de desonerar o Estado da manutenção de estoques e promover a articulação de agentes privados com o setor público nesta tarefa. Interessa saber o quanto os custos sociais e orçamentários se alteraram à proporção que os instrumentos de operacionalização da PGPM foram sendo modificados, diferenciando-se os destinados à agricultura não familiar e aqueles criados exclusivamente para a agricultura familiar. Essa análise não foi feita pela literatura analisada nos parágrafos anteriores.

De modo a obter a avaliação mencionada, o objetivo geral deste artigo é mensurar os custos sociais e orçamentários da política de garantia de preços para o arroz e o milho no período de 1986/87 a 2012/13. A escolha desses produtos deve-se ao fato de eles serem, sistematicamente, contemplados pela PGPM. A seleção desses anos deve-se à disponibilidade de dados para os cálculos dos custos sociais, e, também, por ser um período de significativas mudanças nos instrumentos de execução da PGPM.

\section{Referenciais teórico e analítico}

Para a obtenção das equações que permitem calcular os custos sociais dos programas de compra de excedentes pelo governo (PCEG), preço-subsídios (PPS) e política de seguro de preços (PSP), utilizaram-se os modelos expostos nos estudos de Wallace (1962), Paniago (1969),
Oliveira (1974a) e Paniago e Schuh (1977), e acrescentou-se nova formulação para o caso da política de seguro de preços. Há, neste tópico, uma contribuição do artigo em adotar o mesmo princípio para o cálculo do custo social desses três instrumentos, sendo que as formulações apresentadas nos trabalhos supracitados não estavam detalhadas e nem associadas com a moderna versão da microeconomia, como se faz nesse estudo.

\subsection{Mensuração dos custos sociais da utilização dos diferentes instrumentos de operacionalização da PGPM no Brasil}

Os possíveis custos sociais da adoção de cada uma das políticas de preços em análise podem ser mensurados a partir de duas abordagens teóricas. Na primeira, utilizada na microeconomia das décadas de 1960 e 1970, e exposta em Paniago (1969, p. 76), considera-se que a área total abaixo da curva de demanda e à esquerda de dada quantidade representa a utilidade total dos consumidores para aquela quantidade, enquanto a área abaixo da curva de oferta representa o custo de produção para elaborar aquele produto. Segundo Fergunson (1980, p. 548),

\footnotetext{
"a demanda representa a avaliação social marginal ou o benefício social marginal derivados de uma unidade adicional do bem em questão. Ou seja, a demanda por cada bem mostra o preço ou o custo marginal do recurso que os consumidores estão dispostos a pagar por uma unidade adicional. Na concorrência perfeita, o preço iguala o custo marginal e, felizmente, o custo marginal constitui o custo marginal do recurso em que uma sociedade deve incorrer, a fim de obter uma unidade adicional. Assim, através do costumeiro argumento 'marginal', o bem-estar social é máximo quando o custo social marginal se iguala ao benefício social marginal, ou quando o sacrifício em termos de recursos que os consumidores estão dispostos a fazer seja exatamente igual ao sacrifício que a sociedade deve fazer para ganhar uma unidade adicional de produto".
} 
Assim, subtraindo-se a utilidade total ganha pelos consumidores, em decorrência de uma política de garantia de preços, dos custos adicionais gerados pela mesma política, obtém-se o custo social líquido da política adotada.

Segundo Oliveira (1974b, p. 33), essas premissas são necessárias para a obtenção de uma medida numérica dos custos sociais dos programas de preço-suporte, mas implicam em aceitar algumas hipóteses adicionais. A premissa de que a área sob a curva de demanda à esquerda de dada quantidade representa a utilidade total daquela quantidade implica aceitar que a utilidade marginal da moeda é constante para todos os consumidores. Já a premissa de que a curva de oferta reflete os custos de oportunidade dos recursos variáveis usados para produzir cada quantidade, definindo exatamente a curva de oferta, não permite fazer considerações intertemporais, de espaço e acerca de externalidades decorrentes da política.

Em uma segunda abordagem, da microeconomia mais recente, os custos sociais dos programas de política de garantia de preços podem ser calculados a partir dos conceitos de excedente do produtor e do consumidor. O excedente do produtor é o benefício obtido pela firma pela venda de um determinado produto, auferido em decorrência do custo marginal da produção daquele bem estar abaixo do preço recebido pela venda do mesmo bem. Já o excedente do consumidor é a sua reserva de mercado, ou seja, o máximo que um consumidor estaria disposto a pagar para adquirir determinada quantidade de um bem. Assim, o custo social de uma política de preços também pode ser obtido subtraindo-se os ganhos líquidos de excedente do consumidor e/ou produtor do custo direto do governo com aquele programa.
Como se mostrará à frente, o custo social de uma política de preços mínimos obtido por ambas as abordagens da microeconomia é o mesmo.

Em cada uma das três políticas em análise (PCEG, PPS e PSP), considera-se que o preço estabelecido para o agricultor seja fixado acima do nível de equilíbrio de mercado, de modo a atender os objetivos principais da PGPM. Se o preço não for fixado acima do nível de equilíbrio, a política não será efetiva e não acarretará em custos sociais (PANIAGO e SCHUH, 1977, p. 81).

\subsubsection{Política de preço-subsídio (PPS)}

Considera-se que o mercado de um produto agrícola esteja em equilíbrio no ponto A da Figura 1. Adotando-se os instrumentos baseados em preço-subsídio, fixa-se o preço do produto em $P_{1}$, acima do preço de equilíbrio $\left(P_{0}\right)$; porém, os consumidores pagam preços consistentes com a procura ao nível de produção $Q_{1}$, ou seja, os consumidores pagam $P_{2}$ por unidade do produto e uma transferência de renda $\left(P_{1}-P_{2}\right)$ é utilizada para completar a diferença de preços recebidos pelos produtores. Esta situação está ilustrada na Figura 1.

Em equilíbrio competitivo, a utilidade total corresponde à área $0 D A Q_{0}$. Quando a política preço-subsídio é exercida, a utilidade total torna-se $0 D C Q_{1}$, o que gera ganho de utilidade correspondente à área $Q_{0} A C Q_{1}$. Com a implementação dessa política, recursos adicionais são usados no setor agrícola, cujos custos são representados pela área $Q_{0} A B Q_{1}$. Subtraindo-se a utilidade ganha $\left(Q_{0} A C Q_{1}\right)$ do custo do recurso $\left(Q_{0} A B Q_{1}\right)$, tem-se o triângulo hachurado $\mathrm{ABC}$ na Figura 1, que representa os custos sociais líquidos da política. 
Figura 1. Custos sociais para uma política de preço-subsídio

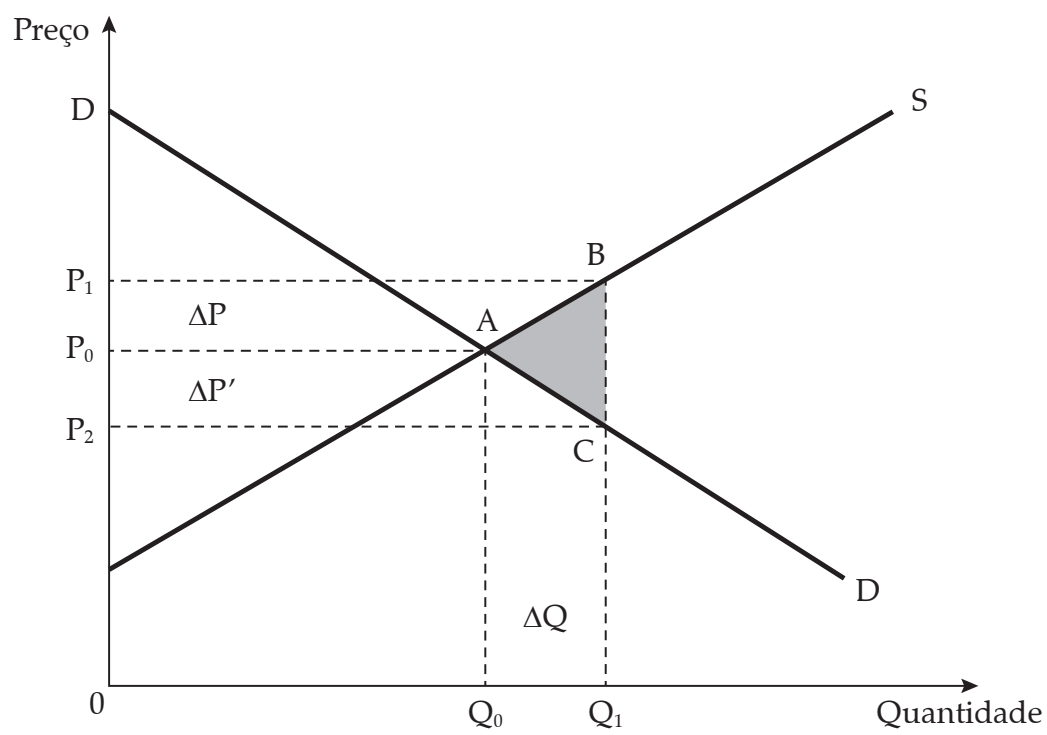

Fonte: Paniango e Schuh (1977).

Outro modo de mostrar que o triângulo hachurado $A B C$ é o custo social da política preço-subsídio é considerar que os consumidores têm um ganho de excedente igual à área $P_{0} A C P_{2}$ e os produtores têm ganho de excedente igual à área $P_{0} A B P_{1}$. Como os gastos do governo com a política são $P_{1} B C P_{2}$, ao descontar desses gastos os ganhos de excedentes supracitados, tem-se o custo social da política dado pela área hachurada $A B C$.

Os instrumentos Prêmio para Escoamento de Produto (PEP) e Prêmio Equalizador Pago ao Produtor (Pepro) ${ }^{9}$ se enquadram como exemplos de política de preço-subsídio. O Prêmio para Escoamento de Produto (PEP), conforme explicam Del Bel Filho e Bacha (2005), consiste em um subsídio dado pelo governo federal para o escoamento do produto de uma região em que há excesso de oferta para outras regiões em que há déficit de determinado produto agrícola. $\mathrm{O}$ governo federal oferta via leilão, por meio da Conab, determinada quantidade de lotes de um produto com um prêmio máximo que ele se dispóe a pagar para quem arrematar o lote pelo

9. A operacionalização do PEP (fluxo operacional) está exposta em Stefanelo (2005, p. 67-72), e uma descrição do funcionamento do Pepro está disponível em Bacha (2012, p. 31). preço mínimo. O arrematante (uma agroindústria ou um exportador, por exemplo) será aquele que ofertar ou aceitar o menor prêmio. Assim, ao final da venda, o produtor rural recebe o preço mínimo pago por um agente da iniciativa privada e este agente, por sua vez, recebe do governo o prêmio arrematado em leilão. Este instrumento garante ao produtor ou a sua cooperativa o preço mínimo, sem a necessidade de o governo adquirir e estocar o produto.

Pelo exposto na Figura 1, utilizando o PEP, o preço mínimo é fixado em $P_{1}$, de modo que o arrematante do lote lançado pelo governo paga aos produtores $P_{1}$. O governo paga aos arrematantes um prêmio, dado pela diferença entre $P_{1} \mathrm{e}$ $P_{2}$. Assim, os produtores recebem $P_{1}$ e os consumidores pagam $P_{2}$.

O Prêmio Equalizador Pago ao Produtor (Pepro) é um instrumento semelhante ao PEP, no sentido de que permite ao governo garantir o preço mínimo ou outro preço de referência ao produtor, sem que o governo precise adquirir o produto. Neste caso, no entanto, o governo realiza um leilão, por meio da Conab, e paga aos produtores um prêmio para que eles vendam a sua produção pelo preço de mercado $\left(P_{2}\right)$. Assim, os 
consumidores pagam $P_{2}$; os produtores recebem $P_{2}$ dos consumidores e, adicionalmente, a subvenção paga pelo governo de $\left(P_{1}-P_{2}\right)$. Da mesma forma que no PEP, o governo arca com a diferença entre $P_{1}$ e $P_{2}$.

A área do triângulo $A B C$, da Figura 1, que traduz o custo social da utilização da política preço-subsídio, pode ser calculada da seguinte forma:

$$
\begin{aligned}
& S(Q)_{A B C}=\frac{\text { base } \cdot \text { altura }}{2} \\
& S(Q)_{A B C}=\frac{\left(\Delta P+\Delta P^{\prime}\right) \cdot \Delta Q}{2}
\end{aligned}
$$

O incremento relativo de preço implicado pelo preço mínimo $\left(P_{1}\right)$ em relação ao preço de equilíbrio $\left(P_{0}\right)$, que é a taxa de crescimento do preço, $r$, é dado por:

$$
\begin{aligned}
& r=\left(\frac{P_{1}-P_{0}}{P_{0}}\right)=\frac{\Delta P}{P_{0}} \\
& \Delta P=r \cdot P_{0}
\end{aligned}
$$

A variação na quantidade ofertada $(\Delta Q)$, decorrente do fato de o preço mínimo ser mantido acima do preço de equilíbrio, pode ser expressa em termos da elasticidade-preço da oferta $(e)$ :

$$
e=\frac{\Delta Q / Q_{0}}{\Delta P / P_{0}}
$$

Rearranjando os termos, tem-se que:

$$
\begin{aligned}
& e=\frac{\Delta Q}{\Delta P} \cdot \frac{P_{0}}{Q_{0}} \\
& e \cdot \Delta P \cdot Q_{0}=\Delta Q \cdot P_{0}
\end{aligned}
$$

Substituindo a expressão (4) em (7), obtém-se:

$$
\begin{aligned}
& e \cdot r \cdot P_{0} \cdot Q_{0}=\Delta Q \cdot P_{0} \\
& \Delta Q=e \cdot r \cdot Q_{0}
\end{aligned}
$$

A redução de preço necessária em relação ao preço de equilíbrio para que a demanda absorva todo o excedente de produção gerado pelo incremento da oferta $\left(\Delta P^{\prime}\right)$ em decorrência do preço mínimo $\left(P_{1}\right)$ pode ser expressa em termos da elasticidade-preço da demanda $(n)$ :

$$
n=\frac{\Delta Q / Q_{0}}{\Delta P^{\prime} / P_{0}}
$$

Rearranjando os termos, tem-se que:

$$
\begin{aligned}
& n=\frac{\Delta Q}{\Delta P^{\prime}} \cdot \frac{P_{0}}{Q_{0}} \\
& n \cdot \Delta P^{\prime} \cdot Q_{0}=\Delta Q \cdot P_{0}
\end{aligned}
$$

Substituindo (9) em (12), obtém-se:

$$
n \cdot \Delta P^{\prime} \cdot Q_{0}=e \cdot r \cdot Q_{0} \cdot P_{0}
$$

ou

$$
\Delta P^{\prime}=\frac{e \cdot r \cdot P_{0}}{n}
$$

Substituindo as equações (4), (9) e (14) na expressão (2), a área do triângulo $A B C$ é dada por:

$$
\begin{aligned}
& S(Q)_{A B C}=\frac{1}{2}\left[\left(r \cdot P_{0}+\frac{e \cdot r \cdot P_{0}}{n}\right) \cdot e \cdot r \cdot Q_{0}\right] \\
& S(Q)_{A B C}=\frac{1}{2}\left[e \cdot r^{2} \cdot Q_{0} \cdot P_{0}+\frac{e^{2} \cdot r^{2} \cdot P_{0} \cdot Q_{0}}{n}\right] \\
& S(Q)_{A B C}=\frac{1}{2} \cdot Q_{0} \cdot P_{0} \cdot e \cdot r^{2}\left(1+\frac{e}{n}\right)
\end{aligned}
$$

Rearranjando os termos, obtém-se a fórmula para o cálculo do custo social da política de preço-subsídio:

$$
S(Q)_{A B C}=\frac{1}{2} \cdot Q_{0} \cdot P_{0} \cdot r^{2} \cdot \frac{e}{n} \cdot(n+e)
$$

Observa-se pela equação (17) que o custo social da política preço-subsídio aumenta à medida que cresce o valor da elasticidade preço da oferta e/ou diminui o valor absoluto da elasticidade preço da demanda. 


\subsubsection{Política de compra de excedentes pelo governo (PCEG)}

Neste caso, o preço do produto $\left(P_{1}\right)$ é fixado acima do nível de equilíbrio $\left(P_{0}\right)$ e os consumidores pagam de acordo com o preço no nível mais alto de produção $Q_{1}$. Os produtores são liberados para produzir ao nível $Q_{2}$, mas o governo é forçado a adquirir, em cada período, a quantidade $Q_{2}-Q_{1}$, a fim de manter o preço ao nível $P_{1}$. O governo utiliza os excedentes de produção adquiridos em programas de bem-estar ou para venda no mercado externo. Esta situação está ilustrada na Figura 2.

Segundo Paniago e Schuh (1977, p. 85), a magnitude dos custos sociais dessa política depende de como o governo dispõe dos estoques. Considera-se, por simplicidade de avaliação, o caso extremo no qual o governo destrói ou doa (caso das compras da agricultura familiar) os estoques adquiridos. Com esta pressuposição, o aumento no excedente do produtor é igual à área $P_{0} A C P_{1}$ e o decréscimo no excedente do consumi- dor é $P_{0} A B P_{1}$. A política resulta, portanto, em um benefício líquido igual ao triângulo $A B C$. Como o custo do programa ao governo é a área $Q_{1} B C Q_{2}$, ao descontar dessa despesa o benefício líquido dado pelo triângulo $A B C$, tem-se que o custo social do programa é a área hachurada dada por $Q_{1} B A C Q_{2}$.

Outro modo de mostrar que o custo social da política é a área hachurada $Q_{1} B A C Q_{2}$ é considerar que há o custo adicional de produção de $Q_{0} A C Q_{2}$, que representa os recursos adicionais utilizados para a produção como resultado de preços mais elevados. Já a área $Q_{0} A B Q_{1}$ representa a redução do nível de satisfação social, decorrente da redução do consumo, de $Q_{0}$ para $Q_{1}$, em função do aumento de preços. Os custos sociais são, portanto, a soma dessas duas áreas, o que é igual à área hachurada $Q_{1} B A C Q_{2}$. Essa área sombreada na Figura 2, que corresponde ao custo social desta política (PCEG), pode ser decomposta matematicamente, subtraindo-se a área do triângulo $A B C$ da área do retângulo $Q_{1} B C Q_{2}$.

Figura 2. Custos sociais para uma política de compra de excedentes pelo governo

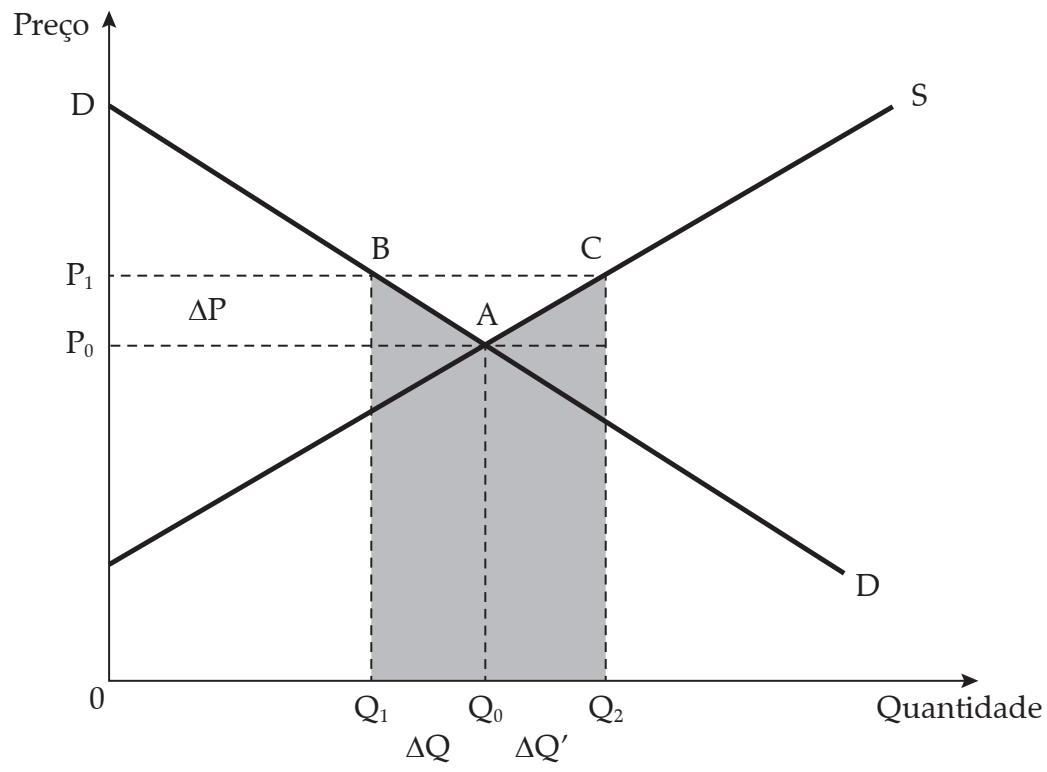

Fonte: Paniango e Schuh (1977). 
A área do retângulo $Q_{1} B C Q_{2}$ é dada pela equação abaixo:

$S(Q)_{Q_{1} B C Q_{2}}=\Delta Q \cdot P_{0}+\Delta Q^{\prime} \cdot P_{0}+\Delta Q \cdot \Delta P+\Delta Q^{\prime} \cdot \Delta P$

Já a área do triângulo $A B C$ pode ser obtida por meio da equação:

$$
S(Q)_{A B C}=\frac{\left(\Delta Q+\Delta Q^{\prime}\right) \cdot \Delta P}{2}
$$

Conhecendo-se as respectivas relações referentes ao aumento percentual no preço de $P_{0}$ até $P_{1}$, dada pela equação (4), e às elasticidades-preço da oferta [equação (6)] e da demanda [equação (10)], obtém-se a área que representa o custo social da adoção de uma política de compra de excedentes pelo governo.

Pelo lado da oferta, interessa o incremento de produção $\Delta Q^{\prime}$. Assim, a elasticidade-preço da oferta pode ser obtida como:

$$
\begin{aligned}
& e=\frac{\Delta Q^{\prime}}{\Delta P} \cdot \frac{P_{0}}{Q_{0}} \\
& e \cdot \Delta P \cdot Q_{0}=\Delta Q^{\prime} \cdot P_{0}
\end{aligned}
$$

Substituindo a expressão (4) em (22), obtém-se a equação (23):

$$
\begin{aligned}
& \frac{e \cdot r \cdot P_{0} \cdot Q_{0}}{P_{0}}=\Delta Q^{\prime} \\
& \Delta Q^{\prime}=e \cdot r \cdot Q_{0}
\end{aligned}
$$

Do lado da demanda, o incremento de produção que interessa é $\Delta Q$. A elasticidade-preço da procura é ${ }^{10}$ :

$$
\begin{aligned}
& n=\frac{\Delta Q}{\Delta P} \cdot \frac{P_{0}}{Q_{0}} \\
& n \cdot \Delta P \cdot Q_{0}=\Delta Q \cdot P_{0}
\end{aligned}
$$

Substituindo a equação (4) em (26), obtém-se:

$$
n \cdot r \cdot P_{0} \cdot Q_{0}=\Delta Q \cdot P_{0}
$$

10. Observa-se que a equação (25) é diferente da equação (10).

$$
\Delta Q=n \cdot r \cdot Q_{0}
$$

Subtraindo a equação (20) da equação (19), obtém-se a expressão:

$S(Q)_{Q_{1} B A C Q_{2}}=\Delta Q \cdot P_{0}+\Delta Q^{\prime} \cdot P_{0}+$

$+\Delta Q \cdot \Delta P+\Delta Q^{\prime} \cdot \Delta P-\frac{1}{2} \Delta Q \cdot \Delta P-\frac{1}{2} \Delta Q^{\prime} \cdot \Delta P$

Substituindo, agora, as equações (4), (24) e (28) na expressão (29), o custo social da política de compra de excedentes pelo governo resulta em:

$$
\begin{aligned}
& S(Q)_{Q_{1} B A C Q_{2}}=r \cdot n \cdot Q_{0} \cdot P_{0}+r \cdot e \cdot Q_{0} \cdot P_{0}+ \\
& r \cdot n \cdot Q_{0} \cdot r \cdot P_{0}+r \cdot e \cdot Q_{0} \cdot r \cdot P_{0}- \\
& -\frac{1}{2} \cdot r \cdot n \cdot Q_{0} \cdot r \cdot P_{0}-\frac{1}{2} \cdot r \cdot e \cdot Q_{0} \cdot r \cdot P_{0} \\
& S(Q)_{Q_{1} B A C Q_{2}}=r \cdot Q_{0} \cdot P_{0}(n+e)+ \\
& +r^{2} \cdot Q_{0} \cdot P_{0}(n+e)-\frac{1}{2} \cdot r^{2} \cdot P_{0} \cdot Q_{0} \cdot(n+e) \\
& S(Q)_{Q_{1} B A C Q_{2}}=r \cdot Q_{0} \cdot P_{0} \cdot(n+e) \cdot(1+r)- \\
& -\frac{1}{2} \cdot r^{2} \cdot P_{0} \cdot Q_{0} \cdot(n+e)
\end{aligned}
$$

Colocando $(n+e)$ em evidência na expressão anterior, obtém-se:

$S(Q)_{\mathrm{Q}_{B} B A Q_{2}}=\left[r \cdot Q_{0} \cdot P_{0} \cdot(1+r)-\frac{1}{2} \cdot r^{2} \cdot P_{0} \cdot Q_{0}\right] \cdot(n+e)$

$S(Q)_{\mathrm{Q}_{1} B A C Q_{2}}=$

$=\left[r \cdot Q_{0} \cdot P_{0}+r^{2} \cdot Q_{0} \cdot P_{0}-\frac{1}{2} \cdot r^{2} \cdot P_{0} \cdot Q_{0}\right] \cdot(n+e)$

$S(Q)_{Q_{B} B A C C_{2}}=\left[r \cdot Q_{0} \cdot P_{0}+\frac{1}{2} \cdot r^{2} \cdot P_{0} \cdot Q_{0}\right] \cdot(n+e)$

$S(Q)_{Q_{1} B A C_{2}}=\left[r \cdot Q_{0} \cdot P_{0} \cdot\left(1+\frac{r}{2}\right)\right] \cdot(n+e)$

$S(Q)_{Q_{1} B A C Q_{2}}=r \cdot Q_{0} \cdot P_{0} \cdot(n+e) \cdot\left(1+\frac{1}{2} r\right)$

$\mathrm{Ou}$, rearranjando os termos da equação (37), tem-se: 


$$
S(Q)_{Q_{B} B A C Q_{2}}=\frac{1}{2} \cdot r \cdot Q_{0} \cdot P_{0} \cdot(n+e) \cdot(2+r)
$$

As equações (37) e (38) permitem o cálculo do custo social de uma política de compra de excedentes pelo governo. Das equações (37) e (38), infere-se que os custos sociais aumentam à medida que se elevam as elasticidades-preço da oferta (e) e da demanda (n) e, também, variam diretamente com o aumento percentual do preço acima do nível de equilíbrio competitivo $(r)$.

As Aquisições do Governo Federal (AGF) e as compras diretas da agricultura familiar $(\mathrm{CDAF})^{11}$ correspondem a uma política de compra de excedentes pelo governo. Por meio desses instrumentos de PGPM, o governo garante a compra dos excedentes de produção diretamente do produtor rural, ao preço mínimo vigente, e pode formar estoques estratégicos.

\subsubsection{Política de seguro de preços agrícolas (PSP)}

No setor agrícola, as decisões de produção são tomadas pelos empresários meses antes de a venda da safra se realizar. $\mathrm{Na}$ época da comercialização da safra, nada garante que o preço de mercado para o produto será o mesmo que vigorava na época do plantio (OLIVEIRA, 1974b, p. 63). Esse é o risco de oscilações desfavoráveis de preços a que está sujeito o produtor rural. Para reduzir este risco, o governo pode utilizar duas políticas de preços, que implicam em custos sociais distintos. Uma delas é a política de preços antecipados com compra de excedentes e a outra é uma política de seguro de preços, no sistema de contratos futuros, como é o caso do COVPA e do Prop.

O Contrato de Opção de Venda de Produtos Agrícolas (COVPA) é um título emitido pela Conab, ofertado em leilóes a produtores e cooperativas agropecuárias, a um preço determinado,

11. O fluxo operacional das Aquisições do Governo Federal (AGF) está disponível em Stefanelo (2005, p. 60) e o das compras diretas da agricultura familiar (CDAF) está disponível em Stefanelo (2005, p. 102). chamado preço de exercício, com data de exercício futura. Segundo o Plano Agrícola e Pecuário de 2007/2008, o contrato de opção de venda assegura ao seu detentor o direito de entregar ao governo a quantidade de produto vinculada à operação, se o preço de mercado do produto estiver abaixo do preço de exercício à época do vencimento do contrato, desde que atendidas as especificações definidas no contrato. Nesse caso, em que há exercício dos contratos, o produto entregue ao governo irá compor os estoques públicos. O governo pode, entretanto, optar por comprar o produto ou pagar a diferença entre o preço de mercado e o preço de exercício ao detentor do título (DEL BEL FILHO e BACHA, 2005).

O Contrato Privado de Opção de Venda e Prêmio de Risco de Opção Privada (Prop) funciona de forma semelhante ao COVPA; no entanto, o governo concebe uma subvenção econômica a um agente privado para esse lançar opções de venda de produtos agropecuários aos produtores rurais. A operação do Prop ocorre, portanto, em duas etapas. Na primeira, a Conab oferece aos operadores do mercado (geralmente indústrias, cooperativas ou exportadores), por meio de um leilão público, um Prêmio de Risco de Opção Privada, sendo que o vencedor do leilão é o agente que ofertar o maior deságio em relação ao preço máximo de prêmio determinado pelo governo. Vencido o leilão, o arrematante fica obrigado a lançar Contratos Privados de Opção de Venda aos produtores rurais ou a suas cooperativas do mesmo produto, dentro das condições previstas no regulamento e no Aviso Específico sobre a operação. O produtor arrematante do Contrato Privado de Opção de Venda adquire o direito de entregar a sua produção ao lançador da opção, caso o preço de mercado esteja abaixo do preço de referência do contrato na época de vencimento do contrato. Para obter este direito, o produtor rural ou a sua cooperativa paga um prêmio ao lançador da opção e vence o leilão aquele produtor que ofertar o maior prêmio (MENDES e PADILHA JÚNIOR, 2007, p. 348).

Se o governo adotar uma política de "seguro de preços agrícolas" ao invés da política universal 
de garantia de um preço mínimo, o próprio setor agrícola paga o prêmio do risco assumido de queda de preços na época da safra. Nesse caso, a agricultura incorre num custo monetário adicional em relação à política de preços mínimos, se desejar afastar o risco de preço decorrente da oferta abundante e, assim, a curva de oferta sem risco, que redundaria da adoção dessa política, deve se situar à esquerda da curva S; é a curva $S^{\prime}$ na Figura 3.

A curva S representa, portanto, a curva de oferta com possível garantia de preço (o preço mínimo), ou seja, representa a "promessa" de compra pelo governo. Já a curva S' é a curva de oferta com seguro garantido de preços, pois ao vender um contrato de venda futura, o lançador deste contrato fica obrigado a adquirir o produto na época do vencimento do contrato, se o titular do mesmo assim desejar.

A diferença básica entre uma política de garantia de preços mínimos e uma política de seguro de preço está em quem paga o prêmio do risco. No caso da política de preços mínimos, ele é transferido a toda a sociedade; no caso da política de seguro de preço, ele é pago pelo próprio setor agrícola. Assim, a curva S' estará acima da curva S exatamente no montante do prêmio necessário para cobrir os riscos (OLIVEIRA, 1974a). O prêmio de seguro cobrado do setor na produção de equilíbrio (ou o quanto os agricultores pagariam para participar de um sistema de preços futuros) é medido pela distância entre os pontos $\mathrm{A}$ e $\mathrm{A}^{\prime}$ na Figura 3. O ponto E é o novo ponto de equilíbrio com a implementação da política de seguro de preço.

Para o cálculo do custo social de uma política de seguro de preços, com utilização de contratos futuros, considera-se que só haverá custo social quando os contratos forem exercidos pelos produtores, de modo que se tornam uma aquisição de produtos agrícolas pelo governo. Nesse caso, os custos sociais oriundos desta política consistem no somatório das áreas $Q_{0} E A^{\prime} Q_{1}$ (custo adicional do uso de recursos) e $Q_{0} E F Q_{1}^{\prime}$ (perda de utilidade no consumo). A área $Q_{0} E A^{\prime} Q_{1}$ representa os recursos adicionais utilizados para a produção como resultado de preços mais elevados (que são os preços de exercício da opção). Já a área $Q_{0} E F Q_{1}^{\prime}$ corresponde à redução no nível de satisfação social, decorrente da redução do

Figura 3. Custos sociais para uma política de seguro de preços agrícolas

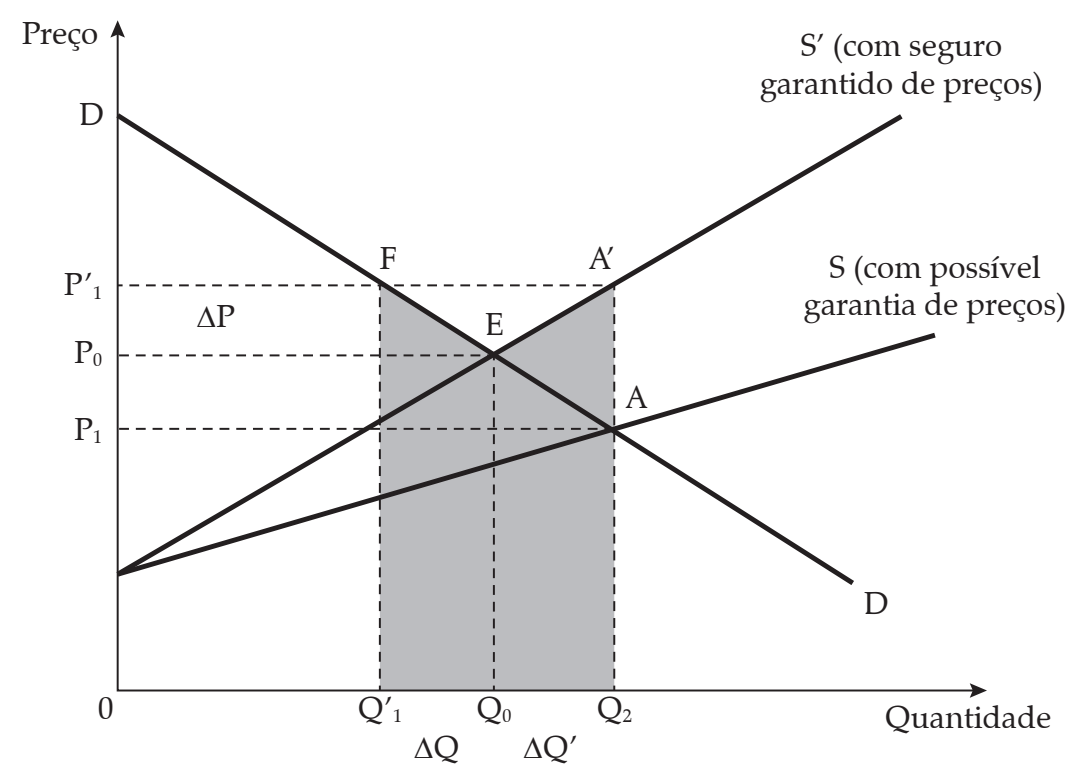

Fonte: Adaptado de Oliveira (1974a). 
consumo em função do aumento de preços. A área sombreada na Figura 3, que corresponde ao custo social desta política, pode ser decomposta matematicamente, subtraindo-se a área do triângulo $E F A^{\prime}$ da área do retângulo $Q_{1}^{\prime} F A^{\prime} Q_{1}$. Ainda que tenham semelhanças de formatos, as Figuras 2 e 3 têm pontos de coordenadas distintos.

De forma análoga à obtenção do custo social para uma política de compra de excedentes, tem-se que a área do retângulo $Q_{1}^{\prime} F A^{\prime} Q_{1}$ é dada pela equação:

$$
S(Q)_{Q_{1 F} A^{\prime} Q_{1}}=\Delta Q \cdot P_{0}+\Delta Q^{\prime} \cdot P_{0}+\Delta Q \cdot \Delta P+\Delta Q^{\prime} \cdot \Delta P
$$

A área do triângulo $E F A^{\prime}$ é obtida por:

$$
S(Q)_{E F A^{\prime}}=\frac{\left(\Delta Q+\Delta Q^{\prime}\right) \cdot \Delta P}{2}
$$

A diferença entre o preço de exercício da opção de venda e o preço de mercado $\left(P_{1}^{\prime}-P_{0}\right)$ é dada pelo aumento percentual em relação ao preço de equilíbrio de mercado $\left(P_{0}\right)$, isto é, $r$, de acordo com a equação (4).

Pelo lado da oferta, o incremento de produção que interessa é $\Delta Q^{\prime}$. Assim, a elasticidade-preço da oferta pode ser obtida como:

$$
\begin{aligned}
& e^{\prime}=\frac{\Delta Q^{\prime}}{\Delta P} \cdot \frac{P_{0}}{Q_{0}} \\
& e^{\prime} \cdot \Delta P \cdot Q_{0}=\Delta Q^{\prime} \cdot P_{0}
\end{aligned}
$$

em que $e^{\prime}$ é a elasticidade-preço da oferta da curva $S^{\prime}$.

Substituindo (4) em (42), obtém-se:

$$
\begin{aligned}
& \frac{e^{\prime} \cdot r \cdot P_{0} \cdot Q_{0}}{P_{0}}=\Delta Q^{\prime} \\
& \Delta Q^{\prime}=e^{\prime} \cdot r \cdot Q_{0}
\end{aligned}
$$

Pelo lado da demanda, o incremento de produção que interessa é $\Delta Q$. A elasticidade-preço da procura é dada pela equação (26). Substituindo (4) em (26) e fazendo o mesmo desenvolvimento que o feito no item 3.1.1, obtém-se:

$$
S(Q)_{Q_{1} F E A^{\prime} Q_{1}}=r \cdot Q_{0} \cdot P_{0} \cdot\left(n+e^{\prime}\right) \cdot\left(1+\frac{1}{2} r\right)
$$

ou

$$
S(Q)_{Q_{1 F E A^{\prime} Q_{1}}}=\frac{1}{2} \cdot r \cdot Q_{0} \cdot P_{0} \cdot\left(n+e^{\prime}\right) \cdot(2+r)
$$

Como na prática é observada a curva $S$, e não $S^{\prime}$, à qual se referem as equações acima, é preciso primeiro estimar a curva $S^{\prime}$ a partir de $S$. Isto é possível a partir do aumento relativo de custos observado à quantidade $Q_{1}$, isto é,

$$
c=\left(P_{1}^{\prime}-P_{1}\right) / P_{1}
$$

As equações (18), (38) e (46) deixam evidente a influência das elasticidades-preço da demanda e da oferta no custo social dos diferentes instrumentos de política de preços, assim como do preço e da quantidade de equilíbrio de mercado. Assim, essas equações só podem ser estimadas após o conhecimento desses parâmetros para cada produto em análise.

\section{Estimativas dos custos sociais e orçamentários dos instrumentos de operacionalização da PGPM no Brasil}

Nesta seção, são apresentadas as estimativas dos custos sociais e orçamentários dos programas da política de suporte de preços utilizada pelo governo federal no Brasil. Essas estimativas estão apresentadas separadamente para os dois produtos em análise, arroz e milho. Como se demonstrou na seção 2 deste artigo, a mensuração do custo social dos diferentes instrumentos de política de preços pode ser obtida conhecendo-se as elasticidades-preço da oferta (e) e da demanda $(n)$ e o preço $\left(P_{0}\right)$ e a quantidade de equilíbrio $\left(Q_{0}\right)$ de mercado em cada ano.

Os cálculos dos custos sociais dos programas de garantia de preços mínimos são bastante sensíveis aos valores das elasticidades-preço da demanda e da oferta. Para tanto, buscou-se na literatura um trabalho que os calculasse 
simultaneamente e para o período contemplado neste artigo. A tese de doutorado de Schwantes (2015) estimou vários modelos simultâneos de demanda e oferta de arroz e milho para os anos de 1986/77 a 2012/13. Entre eles, o melhor modelo implica nas seguintes elasticidades: $n_{\text {arroz }}=-0,0450, n_{\text {milho }}=-0,4469 e_{\text {arroz }}=0,1675 \mathrm{e}$ $e_{\text {milho }}=0,2295$. Para a obtenção do preço de equilíbrio de mercado, foram utilizadas as equações de oferta e demanda definidas por Schwantes (2015). Essas equações foram igualadas e substituíram-se nelas os valores observados para as variáveis predeterminadas das equações em cada ano-safra $t$. Substituindo esse preço de equilíbrio na equação de oferta ou demanda, obteve-se a quantidade de equilíbrio. Por exemplo, igualando-se as equações de oferta e demanda de arroz e substituindo as variáveis predeterminadas nas equações, conforme os valores da safra 1987/1988, obteve-se o preço de equilíbrio de $\mathrm{R} \$ 0,99 / \mathrm{kg}$. Substituindo-se esse valor na equação de oferta ou de demanda, obteve-se a quantidade de equilíbrio per capita, qual seja, $73 \mathrm{~kg}$. Multiplicando-se esse valor pela população de 1987/1988 (139 milhões de habitantes), obteve-se a quantidade de equilíbrio do ano-safra 1987/1988, de 10.163 mil t de arroz.

Para cada produto em análise, considerou-se para o cálculo do custo social os períodos nos quais o maior preço mínimo vigente $(P M M A ́ X)^{12}$ suplantou o preço de equilíbrio de mercado (Preço de Equilíbrio), obtido a partir da igualdade entre as curvas estimadas de oferta e demanda. $\mathrm{O}$ comportamento dos preços observados de mercado, dos preços de equilíbrio obtidos a partir da igualdade entre as equações de oferta e demanda estimadas e o maior preço mínimo vigente entre os preços mínimos regionais para cada produto pode ser verificado graficamente nas Figuras 4 e 5 .

12. Há períodos em que os preços mínimos de cada produto são regionalizados. A Conab forneceu uma planilha de preço mínimo por produto para cada estado da federação. Construiu-se, a partir destes dados, os valores mínimos, médios e máximos das séries de preços mínimos e adotou-se o maior preço mínimo vigente em cada período para comparação com o preço de mercado.
A observação da Figura 4 permite constatar que no período de 1986/87 a 2012/13, o preço mínimo do arroz, considerado em seu nível máximo, esteve abaixo do preço de equilíbrio de mercado, estimado pela interação da oferta e demanda, a partir de 1999/2000. A partir da análise da Figura 4, observa-se uma tendência de redução do preço do quilograma do arroz ao longo do período em estudo, resultado, em grande medida, do processo de abertura da economia brasileira ao mercado internacional, o que levou os preços domésticos a alinharem-se às oscilações de preços de outros mercados e a refletir mudanças na taxa de câmbio. Ressalta-se que os preços mínimos do arroz se reduziram para além dos preços de equilíbrio de mercado: enquanto o preço de mercado do quilograma de arroz reduziu-se em 56,77\% entre 1986/87 e 2012/13, o preço mínimo do quilograma de arroz reduziu-se em $79,46 \%$.

No caso do milho, o preço mínimo, em seu nível máximo, suplantou o preço de equilíbrio, estimado a partir da interação entre as equações de oferta e demanda estimadas, nas safras de 1995/1996, 2005/2006, 2010/2011, 2011/2012 e 2012/2013 (Figura 5). Observou-se tendência de redução dos preços: o preço de mercado do quilograma de milho diminuiu 11,32\% entre 1993/94 e 2012/13, ao passo que o valor mínimo do quilograma de milho diminuiu $32,07 \%$ neste mesmo período, o que mostra o enfraquecimento da política de garantia de preços agrícolas.

Os resultados das estimativas dos custos sociais para cada produto estão apresentados, respectivamente, para arroz e milho, nas Tabelas 1 e 3 , e foram obtidos aplicando-se as fórmulas (18) para a política de preço-subsídio (PPS), (38) para a política de compra de excedentes pelo governo (PCEG) e (46) para a política de seguro de preços (PSP), apresentadas na seção 2. Essas tabelas apresentam, ao seu final, a análise de sensibilidade dos cálculos dos valores de PPS e PCEG caso se utilizem outros valores de elasticidade-preço da demanda e da oferta do que os adotados no presente artigo. Ressalta-se, no entanto, que os valores utilizados procederam de equações robustas do ponto de vista econométrico. 
Figura 4. Preço de equilíbrio ${ }^{1}$, preço mínimo² e preço de mercado ${ }^{3}$ do quilograma de arroz (1986/87-2012/13)

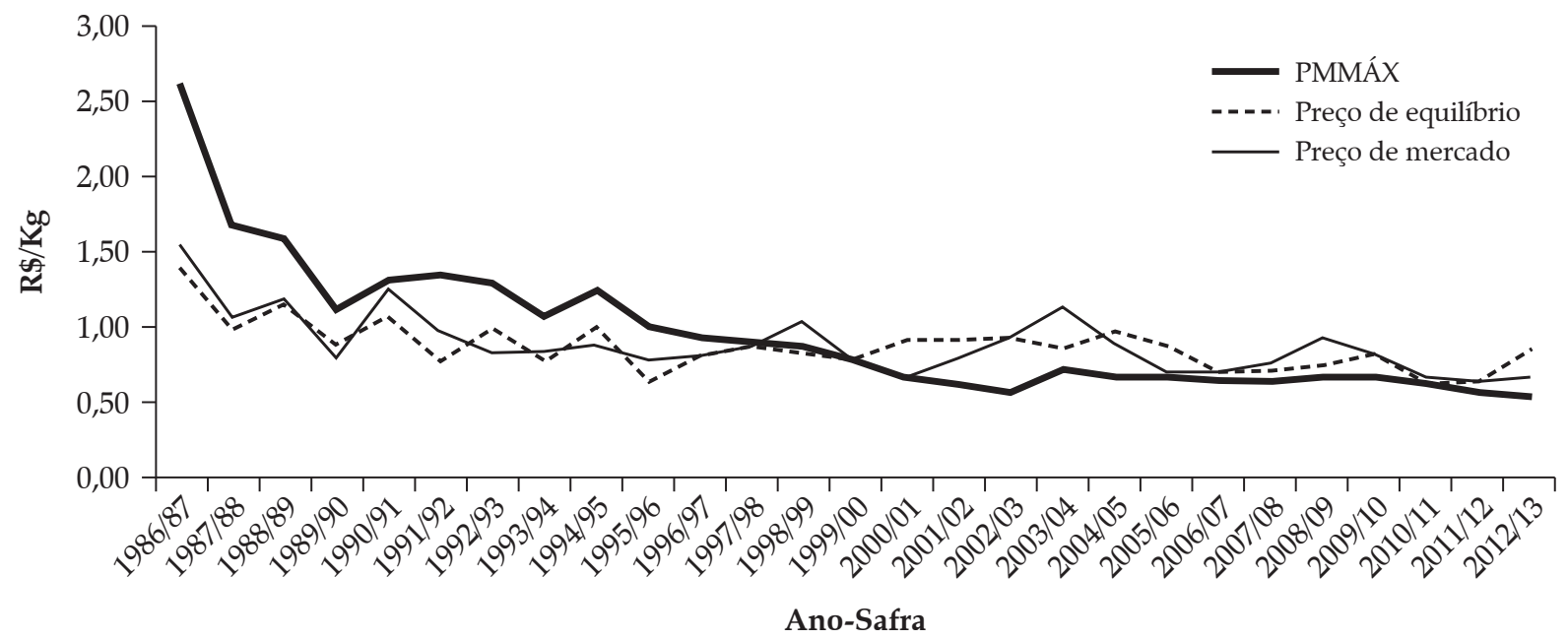

Fonte: ${ }^{1}$ Estimado a partir da interação das equações de oferta e demanda de arroz; ${ }^{2} \mathrm{Conab}(2013) ;{ }^{3}$ IEA (2013).

Figura 5. Preço de equilíbrio ${ }^{1}$, preço mínimo ${ }^{2}$ e preço de mercado ${ }^{3}$ do quilograma de milho (1986/87 - 2012/13)

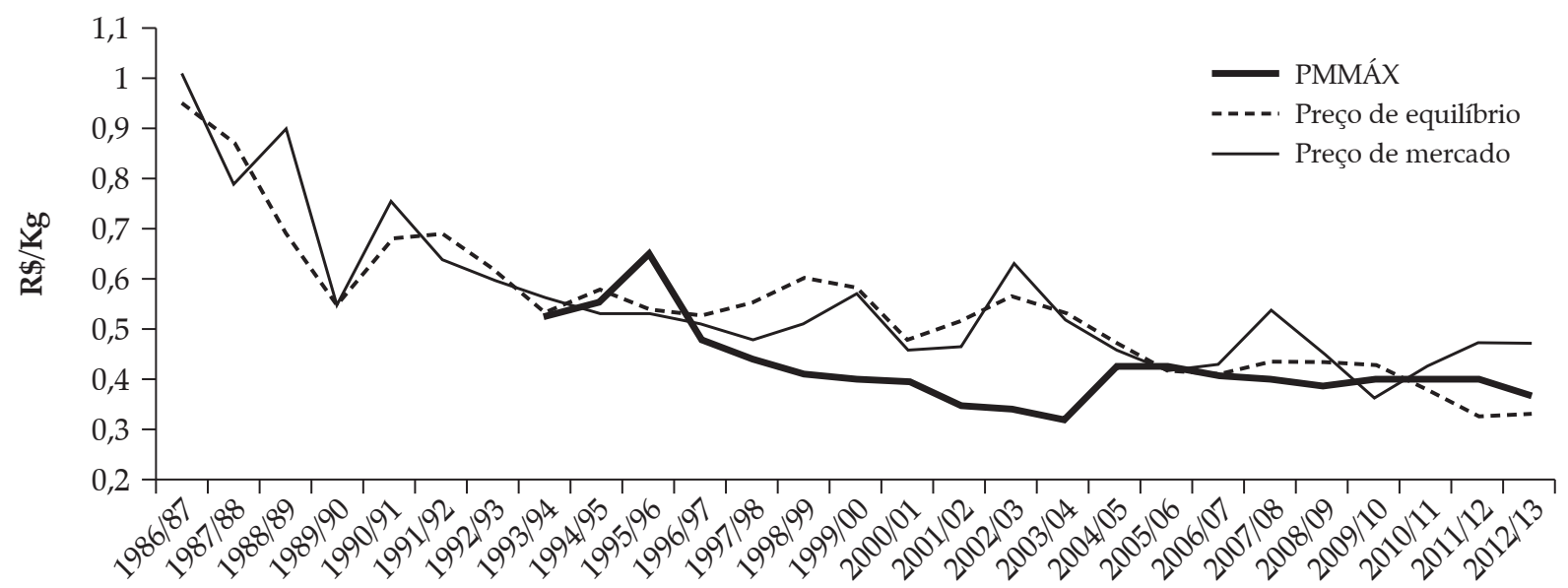

Ano-Safra

Nota: A série de preços mínimos de milho inicia-se em 1993, devido à disponibilidade de dados.

Fonte: ${ }^{1}$ Estimado a partir da interação das equações de oferta e demanda de milho; ${ }^{2} \mathrm{Conab}$ (2013); ${ }^{3} \mathrm{IEA}$ (2013).

Os custos orçamentários para cada um dos programas, por sua vez, estão apresentados nas Tabelas 2 e 4, para arroz e milho, respectivamente. Esses custos foram levantados quando, de fato, os instrumentos da política de garantia de preços foram utilizados.

Para a cultura do arroz, a PGPM geraria custos sociais no período de 1986/1987 a 1999/2000
(Tabela 1), anos-safra em que o preço mínimo vigente apresentou-se superior ao preço de equilíbrio, como exposto na Figura 4. A política de compras de excedentes pelo governo (PCEG), considerada de caráter universal por atender a todos os produtores que desejarem vender a sua produção ao governo, teria sido mais onerosa em termos de custos sociais do que a política 
de preço-subsídio (PPS). Nos anos-safra em que ambas as políticas citadas poderiam ter gerado custos sociais, os custos incorridos pela utilização da PCEG foram mais elevados em termos do valor bruto da produção (VBP) de arroz do que a PPS (Tabela 1).

Nos anos-safra 1986/1987, 1987/1988, 1988/1989, 1991/1992 e 1995/1996, a PGPM alcançou seus picos históricos de utilização, face à redução do crédito rural como política de fomento à produção agropecuária. As aquisições de arroz pelo governo representaram em torno de 60\% do total de AGF nos anos 1988, 1989, 1990, 1991 e 1996 e alcançaram 71\% das AGF em 2000.

A política de seguro de preços (PSP) não geraria custos sociais em nenhum dos períodos em análise para a cultura do arroz. A política de seguro de preços acarreta em um custo ao produtor, que é o prêmio pago por adquirir o direito de exercer uma opção de venda, caso o preço de mercado seja inferior ao preço de referência do contrato na época do seu vencimento. Assim, em comparação com a política de compra de excedentes pelo governo e de subvenção ao preço, essa política não onera a sociedade em termos de custos sociais.

Os custos orçamentários dos diferentes instrumentos de política de garantia de preços foram calculados considerando-se os custos diretos de execução da política. Ou seja, foram considerados apenas os custos de aquisição de estoques ou de subvenção ao preço pago. As despesas administrativas para a operacionalização da PGPM (com equipe e infraestrutura) não foram consideradas, uma vez que não é possível identificar qual parcela das despesas com pessoal da Conab, por exemplo, refere-se à execução da política para um produto específico. Além disso, foram consideradas como receitas o valor do prêmio recebido pelo governo pela venda de contratos de opção de venda de produtos agropecuários. As vendas de produtos agropecuários não foram contabilizadas como receitas dos programas pela indisponibilidade de dados.

Os resultados das estimativas dos custos orçamentários para as políticas de preços operacionalizadas para o arroz, apresentadas na Tabela 2, evidenciam que o custo orçamentário por tonelada de arroz operacionalizada por meio das Aquisições do Governo Federal (AGF) e de Compras Diretas da Agricultura Familiar (CDAF) suplanta o custo da política de seguro de preços (PSP), nos anos em que os contratos foram exercidos, e este custo é mais elevado do que o custo por tonelada do Prêmio de Escoamento de Produto (PEP).

No caso das Aquisições do Governo Federal (AGF) e das Compras Diretas da Agricultura Familiar (CDAF), o custo orçamentário por tonelada adquirida é o mesmo, como se observa nas $16^{\underline{a}}$ e $17^{\mathrm{a}}$ colunas da Tabela 2 . Isto porque a essência dos dois instrumentos é a mesma, ou seja, paga-se o preço mínimo vigente para a quantidade adquirida de cada produto. $\mathrm{O}$ que diferencia os dois instrumentos é o órgão público responsável pela liberação do recurso no caso da aquisição, o Mapa para as AGF e o antigo MDA (atual Secretaria Especial de Agricultura Familiar e do Desenvolvimento Agrário - SEAD) para as CDAF. 


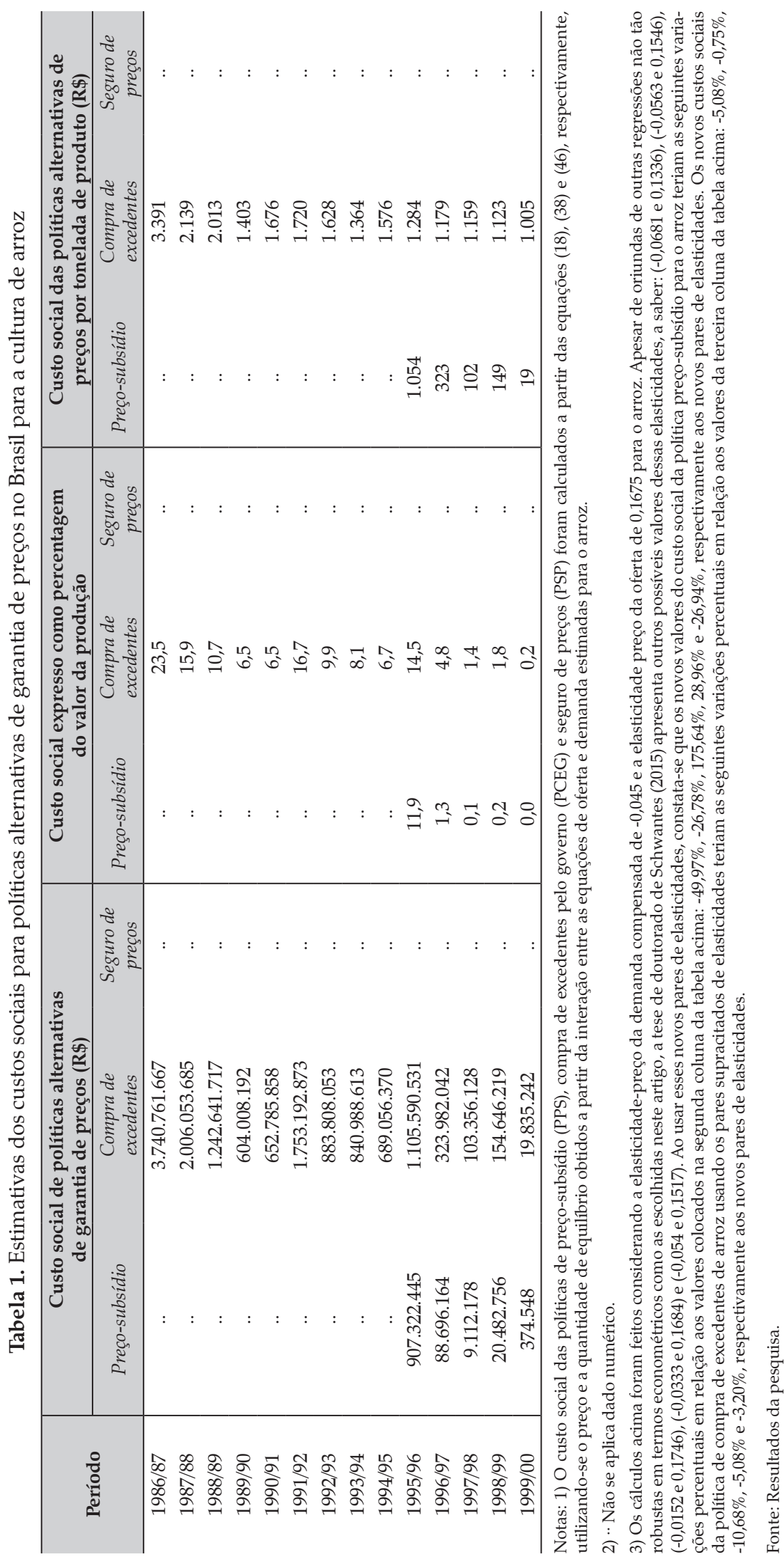




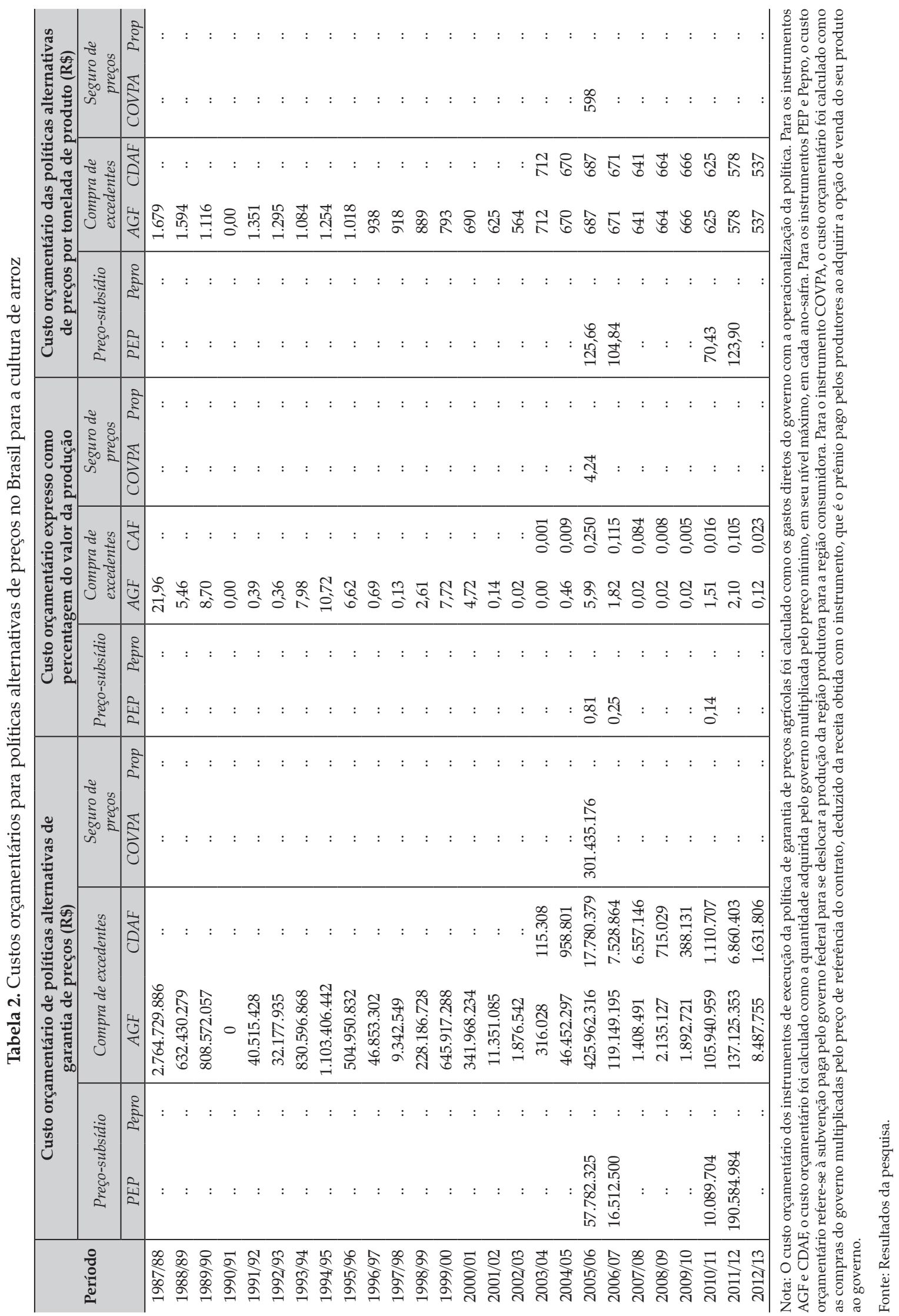




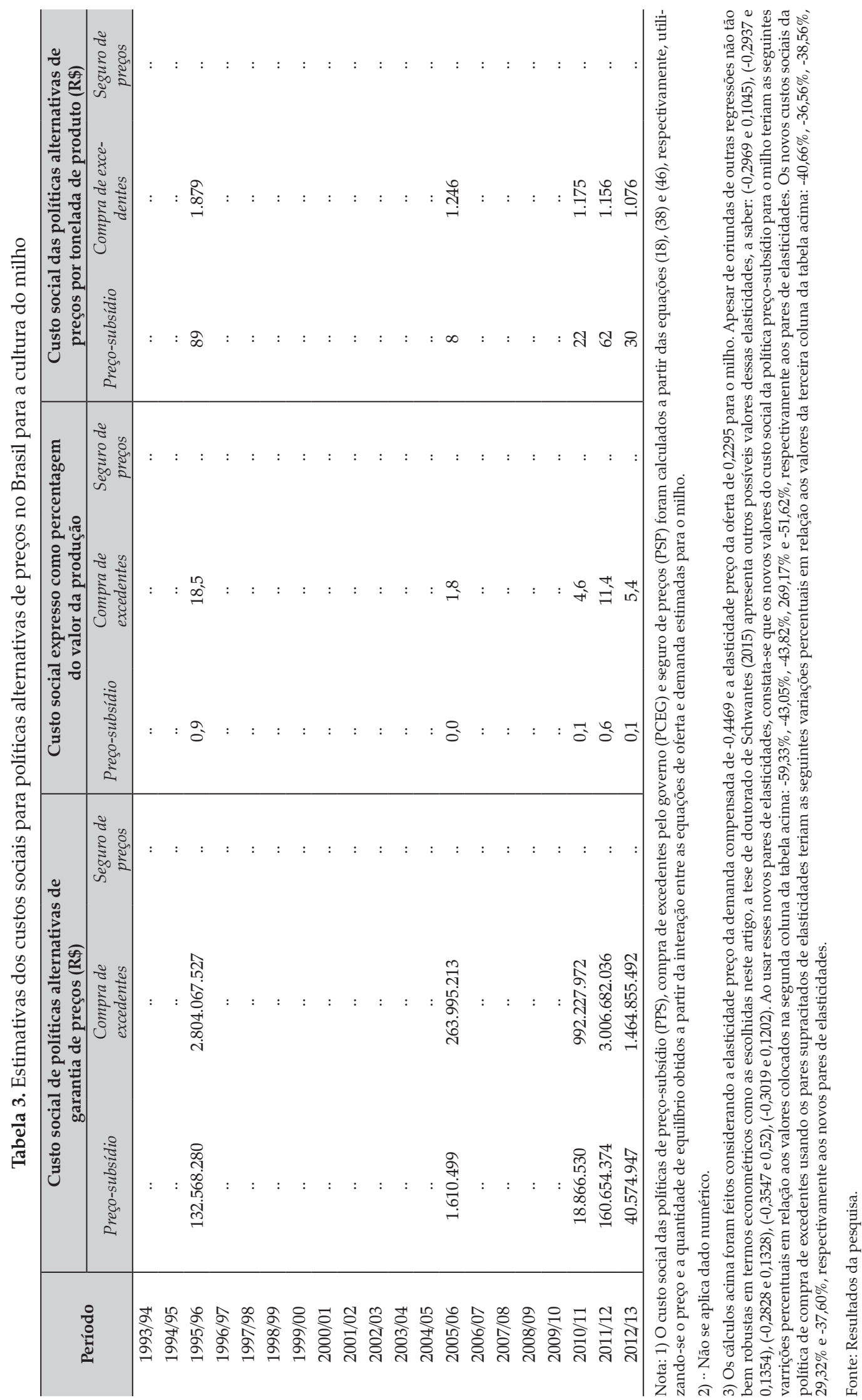




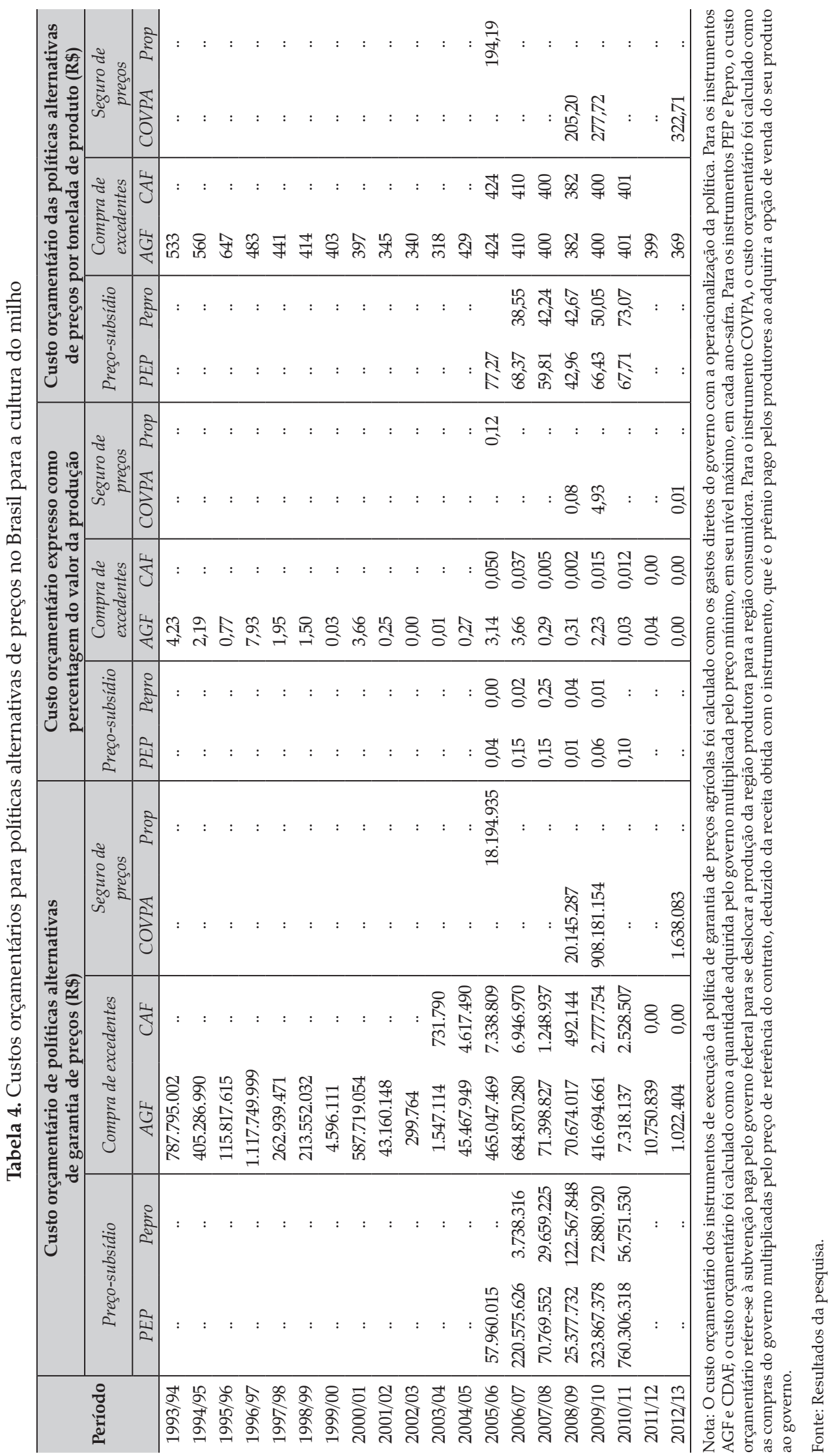


Centrando a análise nos possíveis custos sociais por tonelada de arroz e de milho, apresentados, respectivamente, nas três últimas colunas das Tabela 1 e 3, e nos efetivos custos orçamentários da PGPM por tonelada desses produtos, apresentados respectivamente nas seis últimas colunas das Tabela 2 e 4, constata-se que:

a) Não deveria ocorrer a efetividade dos programas de garantia de preços mínimos para o arroz a partir de 2000, pois, como mostra a Figura 4, a partir desse ano, o preço de equilíbrio de mercado superou o preço mínimo, em seu nível máximo. Também não deveria ocorrer a PGPM para o milho nos anos de 1993/1994, 1994/1995, de 1996/1997 a 2004/2005 e de 2006/2007 a 2009/2010, pois os preços de equilíbrio de mercado suplantaram o preço mínimo (Figura 5). No entanto, há ocorrência dessas políticas para esses produtos em vários desses anos.

b) Ao se comparar a penúltima e antepenúltima colunas das Tabelas 1 e 3, conclui-se que o custo social de uma política de compra de excedentes pelo governo (PCEG) por tonelada é superior ao custo social da política de preço-subsídio (PPS) por tonelada, sendo essa diferença crescente ao longo do período em análise. Por exemplo, em 1995/1996, o custo social da PCEG seria de R \$ 1.277,00 por tonelada de arroz e o custo social da PPS por tonelada de arroz seria de $\mathrm{R} \$ 1.078,00$, sendo o primeiro $18,5 \%$ superior ao segundo. Já no ano-safra 1999/2000, uma possível PCEG para o arroz teria custo social de $\mathrm{R} \$ 999,00$ por tonelada e uma PPS teria custo social de R \$19,00 por tonelada de arroz, com o custo da primeira política ultrapassando em $5.158 \%$ o da segunda política. O mesmo ocorre, em diferente intensidade, para o milho.

c) Ao se comparar os custos orçamentários da AGF por tonelada de arroz (16 a coluna da Tabela 2) com os possíveis custos sociais de uma PCEG por tonelada de arroz (penúltima coluna da Tabela 1), constata-se que a PCEG custou ao governo, nos anos de 1986/1987 a 1999/2000, menos do que teria custado à sociedade. O mesmo ocorre com o milho.

d) Para o milho, a PCEG (AGF e CDAF) possui os custos orçamentários mais elevados, em torno de $\mathrm{R} \$ 400,00$ por tonelada, seguida pelos instrumentos da PSP (COVPA e Prop), cujo valor se elevou de R\$ 194,19 por tonelada em 2005/2006 para R\$322,71 em 2012/2013. A PSP acarreta gastos para o governo se o detentor do contrato de opção de venda exercer o seu direito de venda, no caso do preço de referência superar o preço de mercado. No entanto, o governo recebe o prêmio pago pelos produtores para adquirir o direito de venda, caso a oscilação desfavorável de preço se concretize. Já a política de subvenção ao preço recebido pelo produtor (PPS) é a menos onerosa, pois não exige do governo a compra de produto e a sua armazenagem.

e) O custo social da PCEG representou, em média, $8,36 \%$ do valor bruto da produção (VBP) de milho entre 1993/94 e 2012/13, enquanto o custo orçamentário da política operacionalizada por meio de AGF foi, em média, de 1,62\% do VBP de milho no mesmo período, e por meio de CDAF, de $0,015 \%$. Já o custo social da PPS correspondeu, em média, a 0,35\% do VBP de milho e, finalmente, o custo orçamentário do PEP correspondeu, em média, a $0,085 \%$ do VBP de milho, enquanto o custo orçamentário do Pepro correspondeu a $0,064 \%$ do VBP de milho.

\section{Considerações finais}

A mensuração dos custos sociais dos diferentes instrumentos de operacionalização da PGPM mostrou que os custos sociais da política de compra de excedentes pelo governo (PCEG), 
operacionalizada por meio de AGF e Compras Diretas da Agricultura Familiar (CDAF), são os mais elevados em relação às políticas de seguro de preços (PSP) e de preço-subsídio (PPS). A política de seguro de preços não geraria custos sociais, tanto para o caso do arroz como para o milho.

O fato de se observar o uso de programas de PGPM em anos-safra em que o preço mínimo ficou abaixo do preço de mercado e nos quais, portanto, os programas de PGPM não deveriam ter sido efetivados, é evidência da atuação de grupos de interesses em manterem efetivos os programas de PGPM, de modo que pelo menos os preços de mercado não tenham tendência de queda.

A análise dos custos sociais dessas três políticas de garantia de preços, que têm sido operacionalizadas no Brasil, pode ser utilizada como um indicativo para a orientação de cada instrumento a produtos ou a produtores específicos. Os instrumentos de COVPA, que não gerariam custo social no período de 1987/1988 a 2012/2013, devem ser direcionados aos produtores com maior facilidade de acesso aos mercados. Já os instrumentos de AGF e CDAF, que correspondem à compra de excedentes pelo governo, e que gerariam os maiores custos sociais e os custos orçamentários mais elevados, deveriam ser direcionados aos pequenos produtores ou a produtores isolados, pois é uma política redistributiva.

No que se refere aos custos orçamentários das três políticas de preços em comparação, os instrumentos de subsídio ao preço (PSP) são os menos custosos, destacando-se que, para o caso do milho, a subvenção paga ao produtor (Pepro) apresentou-se, em geral, mais baixa do que a subvenção paga ao arrematante da mercadoria (caso do PEP).

\section{Referências}

ALMeIDA, A. M. de. A Política de Garantia de Preços Mínimos - PGPM e a atuação da Companhia Nacional de Abastecimento - CONAB no período após a abertura comercial: mudança institucional e novos instrumentos. 2014. 206 f. Tese (Doutorado em Ciências, Área de
Concentração: Economia Aplicada) - Escola Superior de Agricultura Luiz de Queiroz, Universidade de São Paulo, Piracicaba, 2014.

ARAÚJO, P. F. C. e SCHUH, G. E. Desenvolvimento econômico e agricultura. In BARROS et al. Fundamentos de Economia Agrícola. FEALQ, Piracicaba, julho de 1988, p. 227-277.

BACHA, C. J. C. Economia e política agrícola no Brasil. 2. ed. São Paulo: Atlas, 2012. 248 p.

BACHA, C. J. C. e CALDARELLI, C. E. Avaliação do desempenho dos novos instrumentos de política de garantia de preços agrícolas de 2004 a 2007. In: CONGRESSO DA SOCIEDADE BRASILEIRA DE ECONOMIA, ADMINISTRAÇÃO E SOCIOLOGIA RURAL, 46., 2008, Rio Branco. Anais... Rio Branco: SOBER, 2008. Disponível em: <http://www.sober.org. br/palestra/9/409.pdf> . Acesso em: 13 mai. 2013.

COELHO, C. N. 70 Anos de Política Agrícola no Brasil (1931-2001). Revista de Politica Agrícola, Brasília, v. 10, n. 03, p. 3-58, jul./set. 2001. Edição especial.

COLOMBINI, R. Principais instrumentos operacionais da ação da Conab na gestão de estoques. In: Companhia Nacional de Abastecimento (Org.). Abastecimento $e$ Segurança Alimentar: o crescimento da agricultura e a produção de alimentos no Brasil. Brasília: Conab, 2008. p. 75-83.

COMPANHIA NACIONAL DE ABASTECIMENTO. Disponível em: <http://www.conab.gov.br/>. Acesso em: 13 fev. 2013.

CONCEIÇÃO, J. C. P. R. Política de preços mínimos e a questão do abastecimento alimentar. Brasília, DF: IPEA, 2003. 29 p. (Texto para discussão, n. 993).

DEL BEL FILHO, E. e BACHA, C. J. C. Avaliação das mudanças na política de garantia de preços mínimos: período de 1997 a 2004. Revista de Economia e Agronegócio, Viçosa, v. 3, n. 1, p. 51-76, jan./mar. 2005.

FERGUNSON, C. E. Microeconomia. 3. ed. Rio de Janeiro: Forense Universitária, 1980. 610 p.

GOLDIN, I. e REZENDE, G. C. A agricultura brasileira na década de 80: crescimento numa economia em crise. Rio de Janeiro: IPEA, 1993 (Série IPEA 138).

INSTITUTO DE ECONOMIA AGRÍCOLA. Banco de Dados. Disponível em: <http://www.iea.sp.gov.br/out/ bancodedados.html >. Acesso em: 15 out. 2013.

LAMOUNIER, W. M. e SILVA, J. T. M. A Política de Garantia de Preços Mínimos no Brasil - Evolução e Perspectivas. REUNA, Belo Horizonte, v. 5, n. 2, p. 25-52, jun. 2000. 
MENDES, J. T. G. e PADILHA JÚNIOR, J. B. Agronegócio: uma abordagem econômica. São Paulo: Pearson Prentice Hall, 2007. 369 p.

OLIVEIRA, J. do C. O papel dos preços mínimos na agricultura. Estudos Econômicos, São Paulo, v. 4, n. 2, p. 77-96, 1974a.

Observações sobre a política de preços mínimos. São Paulo: IPE, 1974b. 105 p. (Série IPE, monográfica, 5).

PANIAGO, E. An evaluation of agricultural price policies for selected food products: Brazil, 1969. 221 f. Thesis (Doctor of Philosophy), Faculty of Purdue University, West Lafayette. 1969.

PANIAGO, E. e SCHUH, G. E. Avaliação de políticas de preços para determinados produtos agrícolas no Brasil. In: ARAÚJO, P. F. C. e SCHUH, G. E. (Orgs.). Desenvolvimento da agricultura: análise de política econômica. São Paulo: Pioneira, 1977. p. 77-125.

PEREIRA, S. R. e PRADO, G. R. Do EGF/COV ao PEP, do AGF ao Contrato de Opção: uma Memória. Revista de Política Agrícola, Brasília, v. 11, n. 3, p. 41-46, 2002.

REZENDE, G. C. de. Política de preços mínimos na década de 90: dos velhos aos novos instrumentos. Rio de Janeiro: IPEA, 2000. 24 p. (Texto para discussão, n. 740).
. A evolução da política de preços mínimos na década de 1990. In: GASQUES, J. G. e CONCEIÇÃO, J. C. P. R. da. Transformações da Agricultura e Politicas Públicas. Brasília: IPEA, 2001. p. 303-314.

SCHWANTES, F. Política de garantia de preços mínimos no Brasil - uma avaliação dos custos sociais e orçamentários para arroz e milho no período de 1987 a 2013. 2015. $137 \mathrm{f}$. Tese (Doutorado em Ciências, Área de Concentração: Economia Aplicada) - Escola Superior de Agricultura Luiz de Queiroz, Universidade de São Paulo, Piracicaba, 2015.

STEFANELO, E. L. A política de garantia de preços mínimos no Brasil: classificação e operacionalização dos seus instrumentos no período 1990-2004. 2005. 176 f. Tese (Doutorado em Engenharia de Produção) Universidade Federal de Santa Catarina, Florianópolis, Santa Catarina, 2005.

VERDE, C. M. V. Modificações recentes na política de garantia de preços mínimos. In: GASQUES, J. G. e CONCEIÇÃO, J. C. P. R. (Orgs.). Transformações da agricultura e políticas públicas. Brasília: IPEA, 2001. p. 315-336.

WALLACE, T. D. Measures of Social Costs of Agricultural Programs. Journal of Farm Economics, Ithaca, v. 44, n. 2, p. 580-594, mai./1962. 